This item was submitted to Loughborough's Research Repository by the author.

Items in Figshare are protected by copyright, with all rights reserved, unless otherwise indicated.

\title{
A Marxist perspective on workers collective action
}

PLEASE CITE THE PUBLISHED VERSION

http://www.palgrave.com

PUBLISHER

Palgrave Macmillan

VERSION

AM (Accepted Manuscript)

LICENCE

CC BY-NC-ND 4.0

REPOSITORY RECORD

Atzeni, Maurizio. 2019. "A Marxist Perspective on Workers Collective Action". figshare.

https://hdl.handle.net/2134/7845. 
This item was submitted to Loughborough's Institutional Repository (https://dspace.lboro.ac.uk/) by the author and is made available under the following Creative Commons Licence conditions.

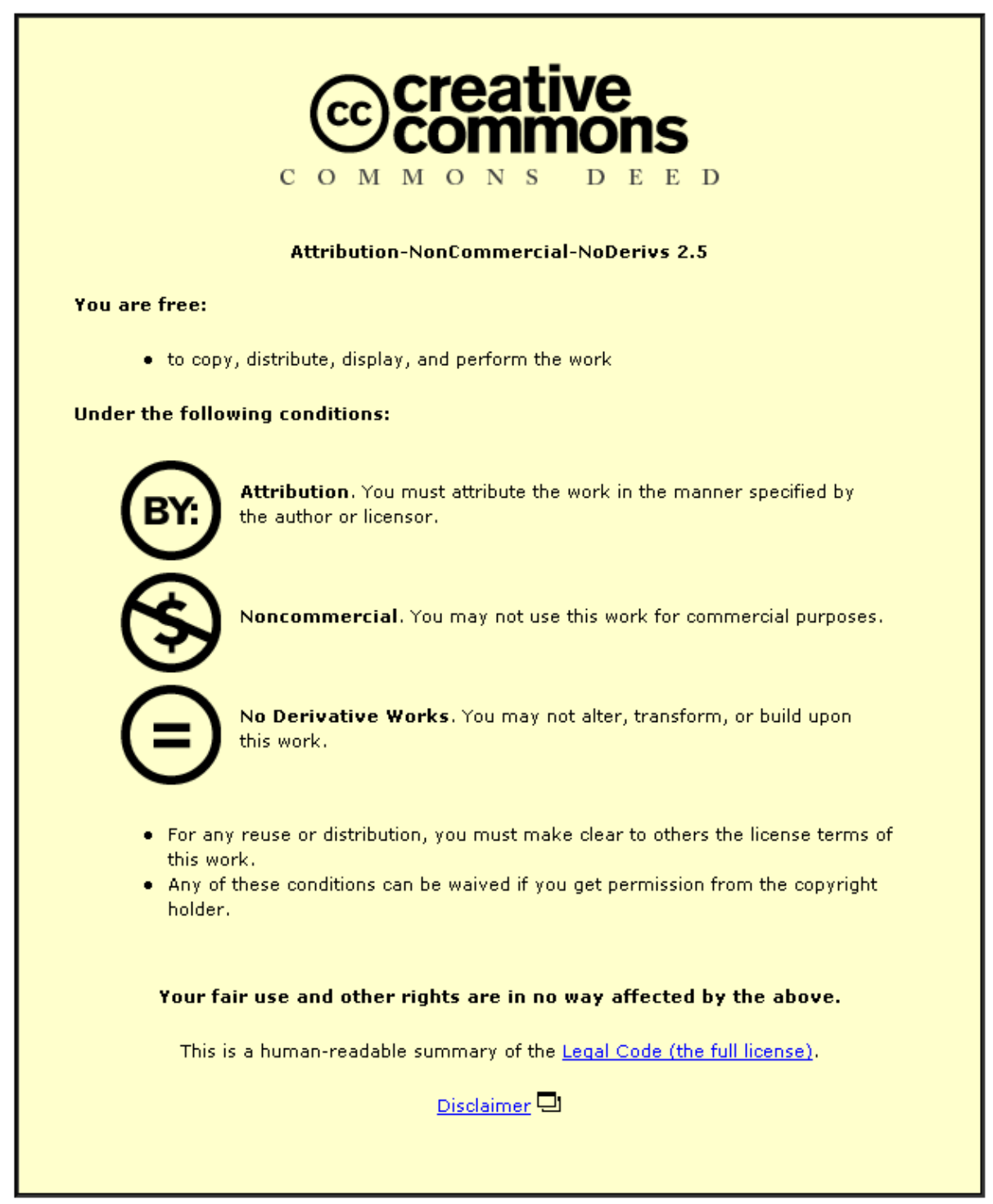

For the full text of this licence, please go to: http://creativecommons.org/licenses/by-nc-nd/2.5/ 


\section{CHAPTER 2: A Marxist perspective on workers' collective action}

\section{Introduction}

What drives workers to periodically contest their surrounding reality and how do they structure their protests? Providing answers to these crucial questions has always been at the centre of Marxist thinking and workplace research. Within this tradition there are key debates around structure and agency, and between subjective and objective conditions in the mobilizations of workers. This chapter aims to add to the theoretical debate and to militant action by proposing a reconstruction of a theory of workers' collective action rooted around four main pillars: the need to avoid subjective and individually based explanations, the centrality of the capitalist labour process' contradictions, the need to constantly demystify capital, the rediscovery of solidarity.

With this background in mind and developing on previous work (Atzeni 2009), the chapter starts with a critique to Kelly's (1998) mobilization theory for the role played in it by the concept of injustice, a subjective, individually framed concept considered as the basis of any mobilization. The next section returns to the capitalist labour process that, insofar as it is the site of both capital valorization and workers' co-operation, constantly creates contradictions, with consequences in terms of workers' opportunities and constrains for collective action. The final section make a point for reconsidering solidarity theoretically central, for being the social relation that expresses the collective nature of the labour process, and relevant as a tool for action and in workers' organising.

\section{Mobilization theory: a critique}

After a decade of a research agenda dominated by human resource management (HRM), of assessments of work under HRM embedded in this ideologically driven paradigm, and in a context of labour and trade unions' retreat, the publication in 1998 of John Kelly's book, Rethinking Industrial Relations: Mobilization, Collectivism and Long Waves, represented a watershed in the field of industrial relations and labour studies. 
For those approaching industrial relations in the tradition of the 1970 s ethnographic workplace studies and the sociology of industrial action and trade unions, Kelly's work was important for two main reasons. First, it offered a theoretical framework for the study of the micro dynamics of workplace conflict and for the understanding of waves of mobilization and counter-mobilization in historical perspective. Second, by putting labour back to the centre stage, basing his analysis in the Marxist vision of society and arguing for the resilience of collectivism in a period of proclaimed individualism it was a political call to counter-balance HRM dominated studies of work.

Because of its wide ranging perspective and critical approach, in the last decade the book became a must read for all those interested in the study of labour organising and collective action and the often cited Marxist-radical reference in the pluralist dominated HRM.

Kelly's main argument, codified in what he calls mobilization theory, is that workplace social relations can be explored and collective action explained and fostered by studying the inter-relations of a set of analytical categories: injustice, leadership, opportunity, organisation. In the model, collective action is reconstructed as the final outcome of a process in which workers' generic feelings of injustice are transformed and made explicit by existing or natural leaders who then attribute the causes of the injustice to the employer and, in presence of a minimum of organisational structure and strategic opportunity, call workers to take action.

Each category and the overall model represent a powerful tool and departure point for empirical research in the analysis of the organising strategies adopted by workers in cases of both mobilization and counter-mobilization. This in recent years has been reflected in a number of works that have used Kelly's framework in relation to leadership (Darlington 2007, 2002 and 2001, Green at al. 2000, Metochi 2002), unions' organising (Gall, 2000b; 2003; Kelly and Badigannavar, 2005), injustice (Brown Johnson and Jarley, 2004) and gender (Cox, Sung, Hebson, Oliver 2007). Although these researches have extended and tested empirically the theory, their conclusions do not put into question Kelly's main assumptions: that mobilization theory is based on injustice and that leaders are pivotal in framing this sense of injustice into a collective action.

Kelly's work has been already commented in full details (Gall 1999 and 2000a), from different perspectives (for a review see Gall 2000a) and at different times (the most recent is Fairbrother 2005). In the following pages I am going to deal particularly with injustice 
as I believe it is crucial to uncover the subjectivity and individuality attached to the concept and thus its unsuitability to explain collective phenomenai.

Despite Kelly's intellectual background and work in the Marxist tradition of industrial relations pervades his mobilization theory, constituting this alone a good theoretical antidote against any type of explanation purely based on subjective experiences, the centrality he assigns to injustice within the theory, ('the sine qua non of collective action', Kelly, 1998, p. 27 and what 'should form the core intellectual agenda for industrial relations' Kelly,1998, p. 126) and particularly in framing workers' interests ('perceived injustice is the origin of workers' collective definition of interests', Kelly, 1998, p. 64) is contradictory. On the one hand, it is made clear that workplace conflict is a feature of the antagonistic relations existing between workers and employers in the capitalist system and that because of this two sets of diverging, often conflicting, interests emerge (Hyman 1975). On the other hand, it is given theoretical relevance to a concept like that of injustice that is flawed for both its appeal to moral, ethical values and for its own indeterminacy.

As Gramsci argued, "the concepts of equity and justice are merely formal...........in a conflict each moral judgement is absurd because it can be based just on the same existing data that conflict tends to modify" (Gramsci 1991, p.179, author's translation from Italian). Thus just or unjust are moral judgements and as such depend on the value and meaning each party in conflict attaches to them. The concepts will reflect beliefs, realities and the power hegemonic relations of a specific society in a particular historical epoch. There will always be injustice, people will always feel aggrieved, exploited, unrewarded but the content of their injustice will never be the same. It is fair enough and common sense to think that people need a motivation to act but the problem will always be to determine the content of their feelings, if a link needs to be established with their mobilization. The moral value attached to injustice and its dependence on hegemonic ideology, necessarily involves a definition of the concept not in absolute but in relative terms.

The use of concepts based on morality is always problematic, especially within a system, like that of capitalism, that appears as founded on freedom while in reality generating coercion and that sees employers and workers' relations in terms of mutual rights and obligations, while obscuring how unequal power struggles constantly change this reality. But this mystification is so strong that even workers in struggle are trapped by the pervasiveness of morality. As Cohen argues, 'Clear-eyed awareness of capital as an unscrupulous class enemy is foreign to workers caught up in a passionate struggle 
in which they see right, and thus ultimately might, on their side. The notion that 'injustice' per se propels workers into struggle is put into question by most of the strike accounts in this book.' (Cohen 2006, p. 206).

In this perspective, once we think about the morality of workplace relations, unquestionable, taken for granted assumptions (management right to manage, capitalist justifications for efficiency and productivity, redistribution of losses but centralisation of profits, market's logic overwhelming presence) occupy the stage, making questions of justice/injustice almost senseless. Here in the workplace is indeed where that change in the dramatis personae to which Marx referred to finally occurs and where the worker 'is timid and holds back, like someone who has brought his own hide to the market and now has nothing else to expect but- a tanning (Marx 1976, p.280).

It is then worth asking, within a system that constantly mystify, how many times workers, everywhere in the world, had to tolerate some form of injustice? Did they always mobilized or we have to think, as Moore (1978) argued, that they accepted the inevitable ${ }^{\mathrm{ii}}$ ? What is the link between their individual feelings of injustice and collective mobilization? Clearly, a theory that wants to explain collective phenomena starting from a subjectively determined, morally grounded basis is deeply flawed.

This problem remains, and is probably reinforced, exactly because real life faces us very often with collective grievances framed within injustice. Thus injustice appears as the flag of new social movements and labour alliances (Waterman and Wills 2001), it is considered functional to a renewal of trade unionism in the "organising unionism" perspective (Heery 2002), it is a valid target for NGO/trade unions' joint campaigns (Ellis 2004) and, more in general, it is certainly useful as concept framing grievances. It is fair to think that together with a mobilization there should be a cognitive moment, a communication, an exchange of ideas among workers in which injustice is framed. As Gall (2000a) suggests workers should feel confident, there should be a surrounding context favourable for action. Yet these are factors that may influence a mobilization but not the necessary conditions.

In the sphere of political proposal and organisation, injustice maintains a catalyst function in summarising in one single powerful word the anger of many. It is in this sense very useful as a concept used by leaders in unifying discontents. But in this perspective may be easily substituted by other moral value- based concepts performing a similar cohesive function (e.g. dignity, inequality, 
fairness) or by leaders' appeals to local traditions of labour antagonism and cultural diversity/opposition to the employer. Thus the problem it is not to deny the existence of injustice in the everyday discourse of labour and political leaders, it is not to deny that workers may really feel a situation as unjust. But rather, that the focus on injustice as the conceptual basis for mobilization, for the argument that we have developed so far, is theoretically flawed and reinforces the idea that collective action in the workplace is all about contesting rights instead of power and class relations.

The simultaneous obscuration of class relations and the conceptual upgrading of injustice to the basis of mobilization does not produces a general theory of collective action but a theoretical framework for action functional to unions' organising. Although injustice is considered as the conditio sine qua non of mobilization, leaders, indeed, are pivotal: they are in charge of moulding injustice, attributing this to the employer and convincing workers to organise and take action.

It cannot be contested that often mobilization follows this temporal sequence and that leaders always play a central role in it, but we should also account for those cases of spontaneous, all of a sudden mobilizations in which no pre-conditions could be detected and where leaders do not play any fundamental role. The recent experience of factories' occupations in post crisis Argentina (Atzeni and Ghigliani, 2007a) is a good example of this trend. Workers occupied their factories spontaneously, without any previous organisation or militant work, because no other options were available in the market. Structural conditions forced them to react and, surprisingly for any vanguard's theory, they did it without any conscious preparatory work but in a very revolutionary way: by challenging property rights, producing under workers' control and redistributing the income in equal parts.

Furthermore, how many times we have witnessed mobilizations out of the union channels or with bureaucratic leaderships forced by the mass to take action? How many times these types of mobilizations go unnoticed? How many times systems of industrial relations impose rules that divide workers and transform the exercise of collective action in a never ending fulfilment of procedures?

A theory of workers' collective action within the Marxist tradition would never be a definitive account, as new forms, times and conditions for action will constantly be reinvented, often in the same course of struggle. But it should be able to identify the structural conditions that both promote and repress workers' action and with this demystify the overall system of appearances that governs 
labour-capital relations. This means in turn a need to return to the labour process as that is the site where both the opposition of labour to capital and yet its dependence on it are constantly reproduced and solidarity linkages are established.

\section{A return to the labour process}

Marx was clear in showing that the particular nature of the commodity labour, its inseparability from the worker, imposed a first, natural, obstacle to the free consumption of it on the part of the capitalists. In order to fully benefits of what bought in the market and to secure that labour power was transformed into concrete productive labour, the capitalist had to find methods to control, direct and discipline workers. 'Through the co-operation of numerous wage-labourers, the command of capital develops into a requirement for carrying on the labour process itself, into a real condition of production. That a capitalist should command in the field of production is now as indispensable as that a general should command on the field of battle (Marx 1976, p.448).

But as generals in a war need to strengthen their control and impose tougher discipline on their troops, so capitalists have to engage in a constant struggle to increase the surplus value generated by the workers through the production process. The driving motive and determining purpose of capitalist production is the self-valorization of capital to the greatest possible extent, i.e. the greatest possible production of surplus-value, hence the greatest possible exploitation of labour power by the capitalist (Marx 1976, p.449). Further, because the drive to valorization will be completed once the product of labour will be sold in the market and because under free competition, the immanent law of capitalist production confront the individual capitalist as a coercive force external to him (Marx 1976, p. 381), capitalists will need to organise production and capture surplus labour in a way that can make them more efficient and thus more profitable of their competitors.

Thus, from the point of view of our employer, the labour process is contemporaneously a process of production and valorization driven by competition and as such imposes on him first the need to find methods, through the organization of the production process and the control of it, to capture and embody in commodities the highest possible amount of surplus labour produced by workers, and then to transform this into surplus value through exchange in the market. Considering that the full realisation of capital, and the possibility of its reproduction, requires both production and exchange, the two 
levels will always be interconnected, with direct consequences for workers. Crisis of profitability generated in the market are indeed immediately 'solved' by individual employers restructuring their production processes either introducing new technology, intensifying and rationalising the use of workers' time, or simply cutting labour cost by reducing wages, introducing flexibility, using or threatening outsourcing and de-localisation, making people redundant.

Because the nature of capital's imperative is valorisation and competition act on the individual capitalists as an immanent and coercive law, the interests of the employers, individually and as a class, will always be tending to conflict with those of workers. In fact no matter how good or bad the employer, how short or long term is his/her business perspective, workers will always be confronted by a system of rules, control, discipline, time management, at the point of production structured around the need to guarantee profitability, that sooner or later will appear and act coercively on them. At the same time, due to their dependence on a wage to live, any changes to their standard of living, both by direct wages' reduction, unemployment, or increase in the price of basic commodities, will be evidence of their interests not been satisfied within the existing system.

The perspective on interests put in evidence once again, the interconnectedness of production and valorization within the capitalist labour process and the need to look at it as a unity. As Cohen argues the issues of valorization and exploitation-the structuring of the organization of labour by the objective of valorization, with its accompanying pressure for reduction of socially necessary labour time, and the contradictions centring on exploitation to which this give rise-surface routinely at the point of production as conflicts of interests between workers and management' (Cohen 1987, p.7).

For our understanding of workers' mobilization, the contradicting and conflicting nature of the capitalist labour process, as organization of production driven by valorization, is crucial. Spontaneous, unexpected, unorganised forms of resistance, the sudden mobilizations of previously loyal workers, the transformations of apparently economistic types of conflict into political ones, are all forms of mobilization that can be explained just by reference to the existence of a structure that constantly reproduces conditions for conflict. The same structure that has justified the historical appearance of trade unions as organisations representing workers' interests and that explains the existence of daily routine struggles at the point of production between workers 
and management. In this latter context, workers may have been forced to accept a particular system of authority and control and may have found ways of accommodating and even co-operating

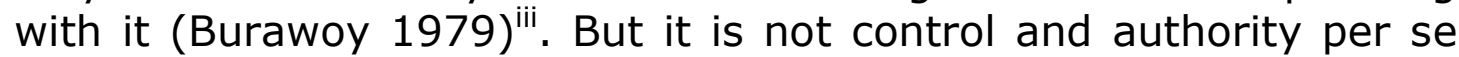
that generates resistance, company's constant drive for profitability within a competitive system is what is everyday jeopardising the reach of consensus, transforming previously accepted practice of management control into an unbearable invasion of workers lives. 'The control exercised by the capitalist is not only a special function arising from the nature of the social labour process, and peculiar to that process, but it is at the same time a function of the exploitation of a social labour process, and is consequently conditioned by the unavoidable antagonism between the exploiter and the raw material of his exploitation' (Marx 1976, p. 449).

Workers' possibilities for resistance and the structuring of their interests as opposed to those of the employers can be inserted, from a theoretical perspective, within the dynamics of productionvalorization-competition. But this does not guarantee the immanence of conflict in real social life, rather the contrary. Living in a capitalist society means for workers not just confront and clash with capital's imperative at the point of production, it is not just to engage in struggles at the workplace over the 'frontier of control', over the rewards-effort bargaining, but it also means to be forced to sell his/her own labour in a labour market that individuals cannot control and be dependent on a wage to live. These coercive conditions are natural, taken for granted and exploitation, in terms of extraction of surplus value, is not part of the workers' daily vocabulary. Capital creates a society that appears as based on freedom and equality. Workers exchange their labour for an average wage, they exchange commodities for commodities in the market. The capitalist buy the right to consume the commodity labour, put the workers in combination to work, add the means of production to the production process, thus 'legally' appropriate the fruits of social labour, return to the market for the final realisation of profit. Every improvement in society is then attributable to capital, exploitation disappears, society depends on capital, workers depend on capital. This until the point that, 'workers are not simply dependent upon the state of capital in general for their jobs and thus their ability to satisfy their needs; they are dependent on particular capitals! Precisely because capital exists in the form of many capitals, and those capitals compete against each other to expand, there is a basis for groups of workers to link their ability to satisfy their needs to the success of those particular capitals that employ them. In short, even without talking about the conscious effort of capital to divide, we can say that there exists a basis for 
the separation of workers in different firms-both inside and between countries' (Lebowitz 2004, p.4).

Our analysis of the structural conditions promoting mobilization could stop at this point. Workers do not only appear, they really are depend on capital to survive and they tend to find ways of accommodating to it. Further to this, their dependence on particular capitals that operate in constant competition creates the conditions for a permanent separation and division of workers. However, at different times and places but continuously they engage in struggles against the system that is exploiting them. Why? Because the capitalist labour process, simultaneously a production and valorization process, is inherently contradictory. When the impelling need of capitalists for profitability brakes even the illusion of an equal exchange relation, exploitation is revealed. Changes in workers' everyday working conditions (more time, more intensity, more dangerous), despotic managerial control (less freedom of movement, tighter definition of tasks, separation of workers), reduction of wages, redundancies, are some of the forms in which this exploitation is represented.

But considering workers' mobilization as a simple reaction to capital's logic, would reduce all conflicts to a matter of wages negotiation and consequently to overemphasise the economistic function, and consciousness, of trade unions. It is certainly true that in the majority of the cases conflicts find a momentary solution in a monetary agreement and that systems of industrial relations find in collective bargaining about wages the key for a compromise between capital and labour. But workers struggle not just about money but also about their conditions as human beings. 'It is quite unrealistic to suppose that because a worker works only for money he accordingly shuts off his mind to his daily experiences at the factory. If he treats his labour as a commodity it does not follow that he expects himself, as a person, to be treated as a commodity. Neither does it follow that he will be prepared to put up with anything if the money is right' (Lane and Roberts 1971, p. 228). Freedom as against control and authority, the creativity of each individual as against the dehumanisation produced by machines, the existence of fully developed human beings as against alienation. 'The arrangements of technology and authority require unthinking obedience. Little wonder then that wildcat strikers sometimes talk as if they have 'done something big for the first time in their lives'. Such people are proclaiming their humanity and protesting that their work situation denies it' (Lane and Roberts 1971, p. 232).

The contradictions of the capitalist labour process create then two different but converging and overlapping sets of motivations for 
workers to struggles. The first more evident set aims to reforms workers' material conditions within the existing system. The importance of these struggles shouldn't be underestimated. First of all, as has been empirically proven, the research in this book representing a further example of this, the workers that have passed thorough a process of struggle and mobilization return to normal life as different, more conscious persons. Secondly, conflict originated for typical bread and butter issues may easily grow in intensity and extend to more radical issues in a context of increasing social and political relevance. Thirdly, these struggles help the formation and establishment of new grass-roots forms of organisation and leadership more democratically oriented, thus promoting a more militant and active participation. The second set of motivations refer more to what Lebowitz (2003) calls the 'worker's own need for development'. Within a system that constantly create new, unfulfilled, needs for workers', 'workers are engaged in a constant struggle against capital-struggles to reabsorb those alien and independent products of their activity, struggles to find time and energy for themselves, struggle propelled by their own need for development' (Lebowitz 2003, p.204)

Thus workers are not just the passive subjects of capital's imperative for profit but have an active role in transforming the system that exploit them, 'no worker known to historians ever had surplus value taken out of his hide without finding some way of fighting back (there are plenty of ways of going slow); and paradoxically, by his fighting back the tendencies were diverted and the forms of development were themselves developed in unexpected ways' (E.P.Thompson 1978, p345 -6, cited in Harvey 2006, p. 115).

Reconsidering the workers' side in explaining their resistance to capitalism has important consequences. First it moves us away from deterministic reconstruction of the social reality and toward a possibility of social change as directly interrelated with the Marxist concept of praxis. Workers' practical activities and experiences gained in the struggle for material benefits are thus essential because through these struggles, while changing their conditions, they change themselves. Second, and a corollary to this, a theory of workers' collective action cannot be reduced either to strategies or to a social psychological account, but should, first of all, reveals and communicate the inner nature of capital mystification. Thirdly, it talks about changes in technology and the organisation of the production process as driven by both the law of competition and workers' pressure. It is because workers depend on capital to survive but also capital depends on workers for profitability, that management and workers will alternate moments of compromise 
and peace with resistance. This, introduces a dynamic element in the understanding of workers' resistance and working class historical formation and help to reject trade unions based pessimistic view about the possibility for social change.

We have started this section by highlighting how the contradictions inherent in the capitalist labour process constantly generate exploitation, re-creating the structure on which conflict can emerge. But the capitalist labour process, as any other labour process intended as creative human activity, it is not just the site of exploitation per se but also the site of cooperation. In fact, despite the tendency to divide workers, to segment work, to separate mental from manual work, the production process imposes at least a minimum level of co-operation. This co-operation if on the one hand becomes functional to capital's valorization, on the other end represents a first associational moment among the collective of workers on which solidarity links may be created. Thus in search for a theory of collective action, the relations between co-operation, solidarity and workers' collective action need to be further explored.

\section{Co-operation, solidarity and workers' collective action}

The co-operation that necessarily takes place in the capitalist labour process is inherently contradictory. On the one hand, the workers 'as co-operators, as members of a working organism, they merely form a particular mode of existence of capital. Hence the productive power developed by the worker socially is the productive power of capital' (Marx 1976, p.451). But on the other hand, 'As the number of the co-operating workers increases, so too does their resistance to the domination of capital, and, necessarily, the pressure put on by capital to overcome this resistance.' (Marx 1976, p.449).

How could workers, whose co-operation is a function of capital and that depend on capital to survive, develop a resistance to it? And by the contrary, why should managerial strategies always tend to divide and create competition among workers? Key to these answers is workers' change of consciousness. Through the cooperation at work the individual worker starts to develop a consciousness of her/himself not just as individual but as part of a group, that shares similar working conditions, that demands for better salaries and job protection and whose interests are overall opposed to those of the employer. The collective labourer, in Marx's term, takes then the scene, reshaping the individuality attached to the labour-wage exchange relation into the collective nature of the labour process. 
In the collective labourer, whereas co-operation at work is the material condition, creating rooms for communication and exchange among workers, solidarity is the social relation that expresses the collective nature of the labour process. Any fruitful attempts to explain workers' resistance must thus depart from the centrality solidarity has in it both theoretically and in the practical, militant discourse.

Stressing this point is even more important when the social sciences, as the overall of society, are invaded by common sense perspectives like the one that considers a minimum level of solidarity as a basic condition for each collective action. As implicit consequence of taking solidarity for granted, the attention of researchers has thus been focused on the identification of preconditions to collective action on which solidarity can develop. As a result solidarity is explained as a function, for instance, of social networks, of a powerful leadership, of the organisational strength of trade unionism, overall confusing cause with effect.

We should start by inverting the analysis: it is because a form of solidarity pre-exists that other organisational developments can follow. The simple fact that labour is a collective activity, implying for workers the need to perform an activity together, generates a sense of mutual dependency and need for support: the embryonic form of solidarity, or what can be called "solidarity not yet activated". This unity has a very practical nature, it is just to perform the job, but it is also the first step in the recognition: a) that the employer has the power to order the forms and times for the execution of the work; b) that who gives this order is by, its very nature, on the other side, opposed and this notwithstanding the need of workers for accommodation within the system. This twofold recognition represents in turn a qualitative step in each worker's consciousness, gradually transforming individual into collective identities. This process which is generated and presupposed by the solidarity built in the co-operative, yet contradictory, nature of the capitalist labour process, is fundamental not just in strengthening workplace based solidarities, those oppositional and spontaneous 'cultures of solidarity' to which Fantasia (1988) refers to, but also in creating the basis for those forms of collective sharing or dialogical democracy that Offe and Wiesenthal consider as the necessary moments for workers to mediate between their contrasting individual and collective interests. 'The logic of collective action of the relatively powerless differs from that of the relatively powerful in that the former implies a paradox that is absent from the latter- the paradox that interests can only be met to the extent they are partly redefined (Offe and Wiesenthal 1980, p.79 emphasis in the original) 
Without the recognition of solidarity as the foundational moment of collective action, we cannot understand the real basis for the success of union activity, the need for workers to be organised, political calls for workers' unity and, by the contrary, all the cases of spontaneous mobilization out of the union channel or in deunionised workplaces.

Conflict and collective action emerge not just by virtue of external forces but because there is an existing fertile soil in that form of embryonic solidarity described above. In this sense, social networks, group or class identification, perceptions of injustice and leaders' action, despite their importance in a collective action, do not represent a conditio sine qua non of it. Instead, they should be understood as vehicles for the circulation and confirmation of solidarity, as elements able to activate a pre-existing embryonic form of solidarity.

By assuming that solidarity is a social relation expressed by the collective nature of the labour process and thus the objective basis of mobilization, we are identifying an abstract but nonetheless real, concrete minimum for its definition and can observe how dominating social relations produce conditions that alter and modify this basic experience and thus the possibility for solidarity of reaching its second level of development, or its "active" form.

These assumptions have an almost natural corollary in the methods we should use to identify solidarity empirically and in its conceptualisation. What I propose here is to think of solidarity as a concept that can best be perceived as a dynamic process, and should be analysed in "progress". We cannot simply measure, detect and search for preconditions of solidarity. This does not necessarily imply the identification of it empirically. There may be preconditions that are considered as good indicators of an already developed form of solidarity (class consciousness, previous struggles and organisation) but these are not at all a guarantee for future mobilizations. On the contrary, we may have mobilizations born out of situations that did not present on the surface any positive indicator of solidarity. Questions such as when and why solidarity occurs, what are the reasons/agents for the development of it into an active form, can be addressed just through an analysis of solidarity in different moments of its development.

By insisting in searching for solidarity as static reality we will end up in a vicious circle pretending to offer concrete, objective signs of the existence of solidarity (because without it we cannot even think of collective action) but without considering how structural conditions 
act on this. The implicit consequence of this mechanism is to consider solidarity almost like a transcendental, evanescent concept that exists but is difficult to be investigated empirically (for instance Fantasia 1995; Portelli 1991) and is, however, easily adaptable to a wide variety of studies: labour process (Beynon 1984; Edwards and Scullion 1982), class consciousness (Fantasia 1988; Rosendhal 1985), cultural and historical accounts of the working class (Bruno 1999, Hanagan 1980).

However, the excess of taxonomy that often in the social sciences creates the problems of definition and classification mentioned above, does not seem to affect workers. A review of historical conflicts from the perspective of those directly involved reveals that their concerns are not about the meaning and the existence of solidarity but rather about the possibility of creating and consolidating it in presence of employers', managements', governments' or trade unions' bureaucracy attempts to break it (for Argentina this may be found in Brennan 1994; Gordillo 1999; James 1988 historical accounts of 1970 s and 1960 s workers' militancy in the city of Córdoba). Workers do not need to search for a definition or to look for solidarity's pre-conditions. They simply have a living encounter with solidarity, a sense of empowerment when it become manifests and drives their action forward or a sense of disappointment and anger when it does not appear, leaving the room to divisions and individualism. Like capitalist exploitation is hidden by the wage relation so solidarity is hidden by the legitimacy of capital command in the workplace and workers' dependency on a salary to live.

This inescapable condition of dependency does not just hinder the possibility of building on solidarity but it also tend to create, as we have seen before, groups of workers fully identified with the particular capital employing them and proud of the quality of their work. 'A fundamental loyalty to the value of production for use rather than exchange, concrete rather than abstract labour, emerges in the bewildered resentment of many workers over their replacement by 'unskilled' workers in a strike, or the transfer of their jobs abroad, despite what for them is the crucial component of worker knowledge and 'quality' of work'. (Cohen 2006, p.194)

All these problems make it extremely risky to establish when and how solidarity will assume its "active" form, this depending on the combination, at a certain epoch, of the forms of labour capital opposition in the workplace and in society as a whole. Unfortunately, we do not yet have a theory of collective action so precise to predict the future. What we can do is to indicate the 
cardinal points in the map for theoretical and empirical analysis and solidarity can be considered as one of these points.

Putting solidarity back at the centre stage of our understanding of collective action is to contribute to a theoretical as well as a political debate. The concept of solidarity has been distorted by decades of ideological and rhetoric use. Yet, once we reframe this concept within the structural contradictions generated by the labour/capital relations in the workplace and the overwhelming dominance of capital in society, we are contributing to demystify and contest taken for granted assumptions about work and 'modern' ways of life. Once inserted in this context, the emphasis on solidarity may be able to provide workers with a clearer understanding of their potential strength and rank and file organisations with a more concrete, everyday, basis for militant discourse and action.

\section{Conclusions and implications for empirical analysis}

This chapter's overall aim has been to offer a reconstruction of workers' collective action from a Marxist perspective. Without pretending to be exhaustive and exegetic in the approach, the chapter has been developed by using Marx's insights into the nature of the capitalist labour process and into the hidden truths of dominant conceptions of work and the political economy. Four main assumptions follow from this background, influencing the overall chapter's reconstruction of collective action. First, attempts to look at workers' collective action as the sum of individuals and as driven by subjective determinations of social reality, like the one associated with injustice, are theoretically wrong and misleading and do not explain the variety and complexity of workers' actions. Injustice may be a useful tool for trade unions' organising and revitalisation but is framed within capital's fetishism. Second and consequent to this, a demystification of the system governing the overall labour-capital relations at the workplace and in society is fundamental. Third, through this demystification it is possible to discover the inherent contradictions of the capitalist labour process generating both resistance and accommodation. Fourth, a theory that aims to communicate and strengthen workers' and their rank and file organizations' knowledge of the constraints and opportunities for collective action, needs to, once the reality of the capitalist labour process is unveiled, reconsider the role of solidarity and its potentialities in framing organisational strategies. Conscious rank and files militants and intellectuals supporting the labour movement should then constantly find ways of breaking capital's rule by demystifying it. In this sense, the emphasis on solidarity is fundamental, for both theory and organisational practice. 
Can we use the theoretical insights developed in this chapter for the analysis of concrete cases of workers' mobilization? How to account for the complexity and multiple determinants of collective actions by emphasising just the contradictions of the capitalist labour process and the solidarity built in workers' co-operation? How can we explain the role of leaders and organisations, for instance, in building and strengthening workers' mobilization?

The answer to these questions is not straightforward and implies decisions about method and approach to research. We may be interested in proposing a theory for analysis and for action that responds to specific categories and that is sequential like the one proposed by Kelly in his mobilization theory, rooted in the injusticeleadership-collective action framework. In this case it is taken for granted that the capitalist labour process generates conflict and that necessary conditions for workers' mobilization are already set within the system. The theory thus offers a clear set of conditions for action that researchers can use and test and activists may consider in the re-orientation and re-thinking of their strategies. Another approach is to enter into the complexity of the social dynamics that produce a workers' mobilization by starting from a reformulation and re-proposition of the conditions that constantly re-produce the basic antagonism between capital and labour. This approach, while re-using and re-formulating Marx's concepts, is at the same time intellectually fundamental to demystify the system of appearances produced by capitalism and methodologically valid to explain the complexity of workers' collective actions. Empirically, the combinations of many different factors, each important on its own, can contribute to explain why workers have mobilized in a specific case. From favourable external socio-political conditions to internal organisational strength, from management violation of rules to workers' explicit confrontational strategy, from charismatic leadership to political parties guiding mobilization, from grass-roots to bureaucracy led mobilization, from mobilization under the banner of injustice to action in solidarity with other organisations, from planned to spontaneous mobilizations, all these are just examples of some of the factors that alone or in combination influence workers' decision to act collectively. But each factor's relevance within specific cases would be lost if the complexity in the understanding of workers' collective action would not be inserted in a parallel understanding of the structural conditions imposed by a system that constantly reproduces 'material relations between persons and social relations between things' (Marx 1976, p. 166). The insistence throughout the all chapter on the capitalist labour process as the site where contemporaneously appearance and reality are contradictorily created is in this perspective fundamental. 
Overall the approach used in this research, while acknowledging the importance of specific factors like leadership or organisation, tries to avoid contingent and subjectively based reconstructions of collective action starting from the definition of the necessary conditions promoting mobilization. This is essential both in terms of defining a generally applicable theory and in terms of methods as it promotes an analysis in the making of the social processes conducting to mobilization. We need to start from the contradictions of the capitalist labour process, from the objective structural conditions of mobilization, to observe in the empirical analysis how the existence of solidarity to workers is contemporaneously obscured and revealed. Theory cannot go further than indicating the possibility for an alternative within the system and the importance, in the interest of workers' emancipation, to struggle for it. After all, praxis remains the best antidote against determinism.

Considering the theoretical and methodological approach proposed in this chapter, the rest of the book will be dedicated to reconstruct in details two different cases of workers' mobilization occurred in two cars' plants of Córdoba, Argentina during 1996-7. The following chapter will set the cases within the context by looking in historical perspective at a range of factors that may have influenced workplace mobilization in Argentina. 